\title{
An extensive review of energy storage system for the residential renewable energy system
}

\author{
M. S. A. Mustaza1 ${ }^{1}$, M. A. M. Ariff ${ }^{2}$, Sofia Najwa Ramli ${ }^{3}$ \\ ${ }^{1,2}$ Faculty of Electrical and Electronic, Universiti Tun Hussein Onn Malaysia, Malaysia \\ ${ }^{3}$ Faculty of Computer Science and Information Technology, Universiti Tun Hussein Onn Malaysia, Malaysia
}

\begin{tabular}{l} 
Article Info \\
\hline Article history: \\
Received Aug 10, 2019 \\
Revised Oct 11, 2019 \\
Accepted Nov 5, 2019 \\
\hline Keywords: \\
Batteries management system \\
Cyber-physical system \\
Energy storage system \\
Lithium-ion \\
Power inverter \\
Renewable energy system \\
Residential energy storage \\
Technology review
\end{tabular}

\begin{abstract}
Energy storage system (ESS) plays a prominent role in renewable energy (RE) to overcome the intermittent of RE energy condition and improve energy utilization in the power system. However, ESS for residential applications requires specific and different configuration. Hence, this review paper aims to provide information for system builders to decide the best setup configuration of ESS for residential application. In this paper, the aim is to provide an insight into the critical elements of the energy storage technology for residential application. The update on ESS technology, battery chemistry, battery charging, and monitoring system and power inverter technology are reviewed. Then, the operation, the pro, and cons of each variant of these technologies are comprehensively studied. This paper suggested that the ESS for residential ESS requires NMC battery chemistry because it delivers an all-rounded performance as compared to other battery chemistries. The four-stages constant current (FCC) charging technique is recommended because of the fast charging capability and safer than other charging techniques reviewed. Next, the battery management system (BMS) is recommended to adapt in advance machine learning method to estimate the state of charge (SOC), state of health (SOH) and internal temperature (IT) to increase the safety and prolong the lifespan of the batteries. Finally, these recommendations and solutions aimed to improve the utilization of RE energy in power system, especially in residential ESS application and offer the best option that is available on the shelf for the residential ESS application in the future.
\end{abstract}

Copyright (C) 2020 Institute of Advanced Engineering and Science. All rights reserved.

\section{Corresponding Author:}

M. A. M. Ariff,

Faculty of Electrical and Electronic,

Universiti Tun Hussein Onn Malaysia,

86400 Parit Raja, Johor, Malaysia.

Email: aifaa@uthm.edu.my

\section{INTRODUCTION}

Developed countries with tremendous economic growth require a massive amount of electrical energy. The energy demand of these countries increase exponentially with time, which $70 \%$ of this demand is supplied using fossil fuel and the remaining $30 \%$ is from renewable sources [1]. The real threat of fossil fuelbased energy depletion raises a serious concern in the power system community. Therefore, it is necessary to shift the dependencies of energy supplies to renewable energy (RE) in order to secure the continuity of the energy resources in the future. Prior to 2010, the development of RE in Malaysia is relatively slow due to insufficient enforcement from the government [2]. However, the Malaysian government implements the Feed-inTariff (FiT) policy in 2010 to accelerate the development. Consequently, the market share of the electricity generated from RE is $4.5 \%$ in 2009 increased to $5.5 \%$ in 2015 despite the increment of total energy demand. Unfortunately, the growth of RE in Malaysia does not depend only on the introduction of the new policy. Technical demand and the stochastic nature of the RE itself play a vital role in making this future a reality. These challenges limit the real 
potential of free and clean energy utilization in Malaysia. According to the Malaysia main electricity provider, Tenaga Nasional Berhad (TNB) 2017 Annual Report [3], the residential customer comprises $82.21 \%$ of their customers. The same strategy has been successfully implemented in Germany since 2004 [4] as they have managed to have $40 \%$ of energy share for RE in 2018. It is well known that the RE sources are stochastic and it is almost impossible to depend on the RE only without compromising the continuity of the electricity to the user. The ESS operates as a reservoir of electrical energy to overcome the uncertainty of RE. Thus, ESS for residential customer plays a vital role to ensure the successfulness to shift the dependency of the fossil-fuel to the RE-based energy resources in the near future.

In the literature, there are several manuscripts that review the latest ESS technologies and development on various applications and diverse focuses. In [2], the researchers discuss the present status of lithium-ion battery technology. The discussion focuses on the electrochemical aspect and potential material to achieve the improvement of the lithium-ion battery's energy and power contents. On the other hand, the studies in [5] and [6] review the technology development of the energy storage system for transport and grid main applications. They focus on the power converter and power storage technologies for various applications. The researchers in [7] discuss the ESS architectures utilized in practice, focusing on the development of the control algorithms to optimize the ESS utilization. The study reported in [8] reviews the maturity of storage energy technologies in order to facilitate the load demand for daily consumption. On the other hand, researchers in [9] review the energy storage system for hybrid electrical vehicles (HEV) application. The report focuses on the evaluation of the technology readiness of the distinct compartment of the vehicles, especially on the electrical propulsion system.

This paper aims to provide an insight into the critical elements of the energy storage technology for the residential application. It is not just providing an update on the ESS technology, this paper discusses in detail about the battery chemistry, battery charging system, battery monitoring system, and power converter system that are vital for the ESS application. This paper discusses the operation, the pro and cons of each variant of these technologies and recommends the best option that is available on the shelf for the residential ESS. To these authors knowledge, this paper provides a fresh perspective of reviewing the available technology for RES as compared to the literature discussed in [10]. Following this introductory section, Section 2 discusses the RE system for the residential customer. Next, Section 3 explains about the battery storage system. Following Section 3, the battery charging and management system for residential utilization is discussed in Section 4. Subsequently, Section 5 discusses the power converter system required for residential utilization. Finally, Section 6 discusses and concludes this study with the remarks of future research opportunities in residential energy storage.

\section{THE RESIDENTIAL RE SYSTEM}

Energy storage technology has a tremendous impact on electrical system utility development especially in the RE integration with the conventional power network. Figure 1 shows the typical block diagram of the residential RE system integration with the electrical grid system.

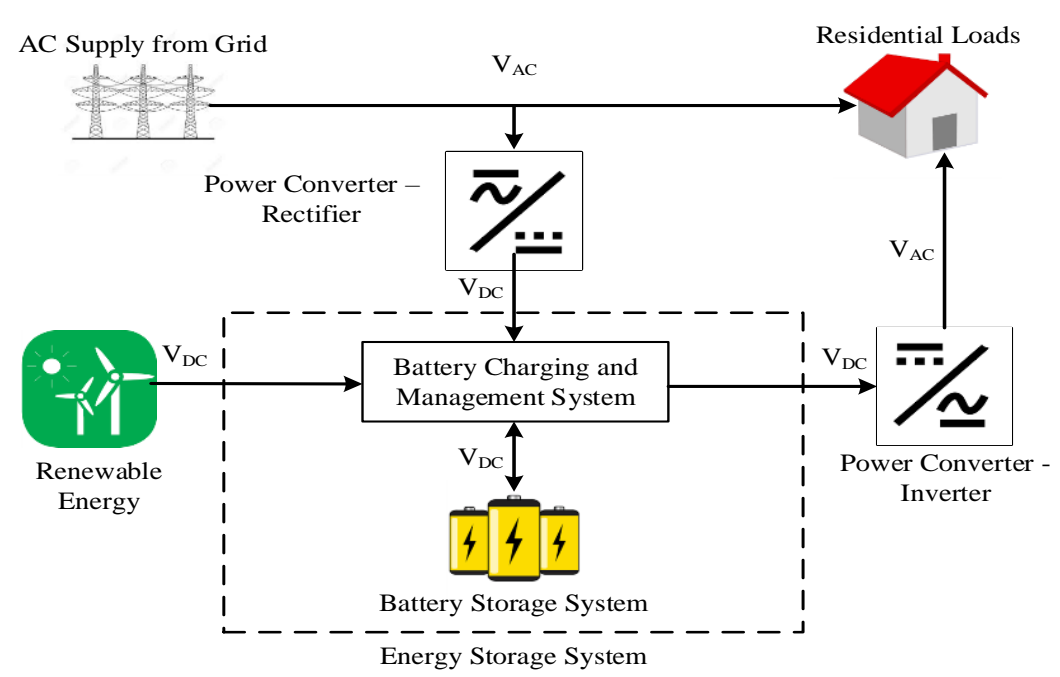

Figure 1. The typical residential RE system 
The residential RE system is slightly different from the solar plant. The system consists of several sub-systems that are vital to ensure the continuity of electricity supply to the residential customer [11]. The renewable energy sources are converted into direct currents to charge the EES when the energy is available. It is well noted that the RE is not always available to the customer. Thus, the EES also could charge itself by converting the energy from the electrical grid system by using a battery charging and monitoring system. The energy gathered in the ESS is utilized by the user via power inverter technology. The inverter is required because most of the loads in the residential sectors need alternating current (AC) supply, while the ESS supply electricity in direct current (DC). This system is also beneficial for the customers in the countries that utilize variable tariff to their customer, where the customer could charge its EES when the price is low and utilize the energy when the price is high [12]. In this paper, the three vital sub-systems: 1) the battery storage system, 2) the battery charging, monitoring, and charging system in the typical ESS for the residential renewable energy system are discussed in detail in the following section.

\section{THE BATTERY STORAGE SYSTEM}

This section elaborates one of the most important parts of the energy storage system, the battery storage system. There are various options that are available to the ESS system builder. Each type of battery has a different performance from one another. While one type may be suitable for one application, it may not be suitable for another type of application. For example, the lead-acid battery has served the automotive industry for over a decade. However, it is not suitable for unmanned aerial vehicle application [13]. Thus, the technical terms that characterized the performance of a battery system are discussed in this section first. Next, this section discusses and compares the performance of all types of battery chemistry. Consequently, the most advanced and currently under rapid development battery chemistry, the lithium-based battery is discussed. All available lithium-based battery chemistries are reviewed, and their performance is compared. Finally, this section discusses the suitability of the battery chemistry available in the market for the RE application for the residential customer.

\subsection{The Characteristic of the Battery Performance}

In practice, there are no one-battery-fits-all for any application. Thus, the system engineer needs to identify the battery that has the characteristic that suits their application the most. There are several important terms that are used to characterize the performance of the battery. Usually, their performance is differentiated in terms of their specific energy, specific power, safety, discharge performance, lifespan, and cost.

Specific energy is defined as the capacity of the energy storage in energy content per unit mass $(\mathrm{Wh} / \mathrm{kg})[14]$. The value of specific energy strongly influences the total weight of the energy storage system. On the other hand, specific power is defined as the loading capability of the energy storage in a unit of (W/kg) [14]. This characteristic requires critical consideration in high powered and fast discharge applications. Next, safety is described as the ability of the energy storage to operate in good condition without causing any harmful damages such as an explosion or health risk to the user [15]. Consequently, discharge performance is described as the characteristics and responses of a battery during its application [16]. The discharge performance of a battery cell is measured by its discharge curve, temperature characteristic, self-discharge characteristic, and discharge rate. Nevertheless, the lifespan of a battery cell is defined as the number of charge and discharge cycle of a battery can maintain before its performance degraded and it becomes no longer suitable any applications. Finally, the cost of a battery cell mainly depends on the active materials used to manufacture the battery. Therefore, it is necessary to optimize the performance of the energy storage system to suit the application during the design process to ensure the cost of the system is optimized.

\subsection{The Performance of Different Types of Battery Chemistry}

Figure 2 depicts the performance of the lead-acid, Nickel Cadmium (NiCd), Nickel Metal Hydrate $(\mathrm{NiMH})$, and Lithium-ion battery chemistries that are available easily in the market. This information is obtained based on the study reported in [17]. The performance of these batteries is compared based on the characteristic discussed prior to this subsection. Rating 0 represents the worst, and rating 10 represents the best performance of the battery chemistry.

Figure 2 shows that the lithium-ion battery outperforms the other battery chemistry in terms of specific energy, specific power, discharge performance, and cost. The figure also shows that the lead acid, NiCd, and NiMH battery are superior as compared to the lithium-ion battery. On the other hand, NiCd has the best battery lifespan as compared to others. However, the difference in terms of the battery lifespan is not significant as compared to the lead acid, NiMH, and lithium-ion battery. 


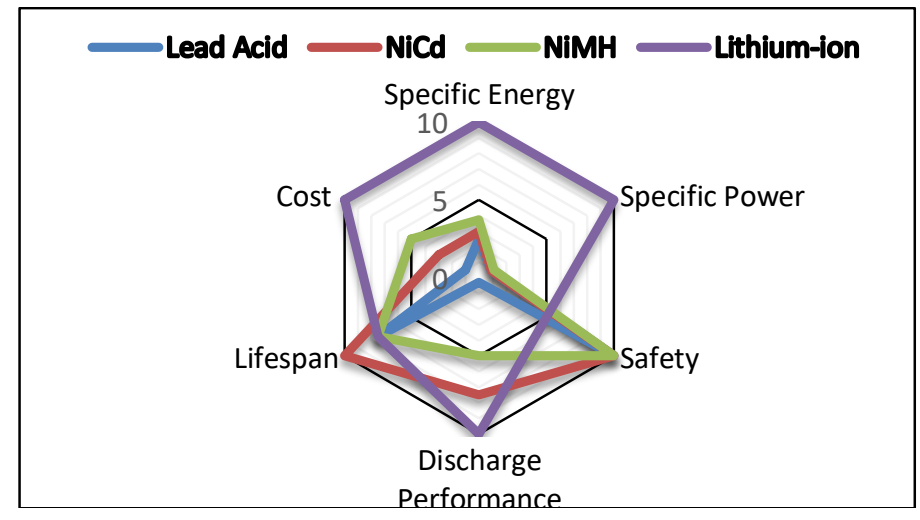

Figure 2. The performance of different types of battery chemistry

This comparative analysis shows that the lithium-ion battery is superior to other battery chemistries. This superiority is one of the reasons that the researchers are concentrated in the development of a lithium-ion battery for the future. Recently, two technology giants, Tesla and Panasonic have formed a strategic collaboration effort to speed up the development of the lithium-ion battery to further improve its specific energy and specific power [18]. As for its predicament in terms of safety, researchers have developed the battery management system (BMS) to ensure the lithium-ion battery operation is within its safety limit.

\subsection{The Performance of Different Types of Lithium-ion Battery Chemistry}

There are several types of lithium-ion based batteries, which are segregated based on the active materials that are combined with the lithium-ion to store the energy. Common active materials used are cobalt, aluminum, manganese, nickel, and titanite [19]. This combination dictates the characteristics and performance of the battery. There are many combinations of battery chemistries that are available. However, only five of the most common battery chemistries are discussed in this paper about its suitability for residential energy storage system application. Lithium Cobalt Oxide (LCO) battery is considered as one of the matured lithium-ion battery technology. As discussed in [13], the development of this battery in term its specific energy and lifespan are considerably saturated. LCO have high specific energy as compared to other lithium-ion battery chemistries. This battery is the most common energy storage technology applied in mobile electronic devices. However, this battery chemistry suffers from low thermal stability, short lifespan and limited specific power.

Lithium Manganese Oxide (LMO) battery have a higher cell voltage compared to the LCO-based battery which is $3.8 \mathrm{~V}$ to $4 \mathrm{~V}$. Therefore, it is suitable for the application that requires high voltage such as power tools, as well as hybrid and electric vehicles. Furthermore, LMO superior to LCO in terms of thermal stability, safety, and production cost. However, the specific energy, lifespan, and discharge performance of LMO are slightly less than LCO. Next, Lithium Titanite Oxide (LTO) battery promotes the highest safety, discharge performance, and lifespan as compared to other battery chemistries discussed in this paper [20]. This characteristic is because the volume expansion of the battery electrodes during the intercalation of lithium is below $0.2 \%$ [20]. This active material configuration leads to an advantage of LTO over other materials for high power application. Unfortunately, the drawback of this battery chemistry is its low specific energy due to the titanite composition that consists of small voltage hysteresis for the charge-discharge profile. Therefore, this battery chemistry is not suitable for the application that requires high specific energy battery such as for an aerial vehicle, and mobile communication device.

Lithium Nickel Cobalt Aluminum Oxide (NCA) battery has higher specific energy, higher specific power and longer lifespan as compared to LCO, LMO, and LTO batteries. Due to its high specific energy, NCA has been the center of attention and commercialized by many manufacturers such as Panasonic, Gaia and Nissan [21]. However, NCA lacks in terms of safety because of its low thermal stability that makes this battery is not very popular for specific application such as in aviation, residential and mobile devices. Moreover, it is relatively expensive to produce as compared to other battery technologies. Lithium Nickle Manganese Cobalt Oxide (NMC) is another successful lithium-ion battery technology. This battery combines four elements (lithium, nickel, manganese, and cobalt) to the battery. The ratio between nickel, manganese, and cobalt are 3:1:1, respectively [22]. Combination of nickel and manganese reduce the needs for cobalt in the manufacturing process. Cobalt is hazardous to the environment. Over the past six years, the collaboration between Tesla and Panasonic has successfully reduced the dependency on cobalt in the development of the NMC battery by 60\% [23]. Consequently, the production cost and the safety of the NMC battery cell are less than NCA. Although it is cheaper and safer, it has relatively similar discharge performance, specific energy, specific power, and lifespan as compared with NCA. 


\subsection{Suitability of the Battery Chemistry for the Residential RE System}

Figure 3 summarizes the performance of lithium-ion battery chemistries discussed in this paper. The figure shows the performance comparison between the LCO, LMO, LTO, NCA, and NMC. From the figure, the performance of the batteries is categorized based on their characteristics, respectively. In this system, rating 0 represents the worst, and rating 10 represents the best performance of the battery chemistry.

From the figure, it shows that the LTO battery outclasses other battery technologies in term of safety, discharge performance and lifespan. However, LTO shares the same level of specific power with LMO, NCA, and NMC. In terms of specific energy characteristic, LCO, NCA, and NMC share the same level of performance. It is noticed from the figure that the cost of production for LCO, LMO, and LMC are cheaper as compared to NCA. On the contrary, LTO is the most expensive lithium-based battery technology to be produced. Although all characteristics are crucial for the residential RE system, the system engineer is more concerned with the specific energy and the specific power of the battery [24]. This is because the predicament of other battery characteristics, especially safety, discharge performance, and lifespan, can be compensated with an additional controller that manages the charging and the discharging process of the battery. NMC fits the bill as its specific energy, specific power and cost are excellent (rated at 10), while its safety, discharge performance, and lifespan are good (rated at 8). Conclusively, NMC delivers an all-rounded performance as compared to other battery chemistries. Thus, in the author's knowledge, it is the most suitable type of battery chemistry for the ESS of the residential RE system application to date.

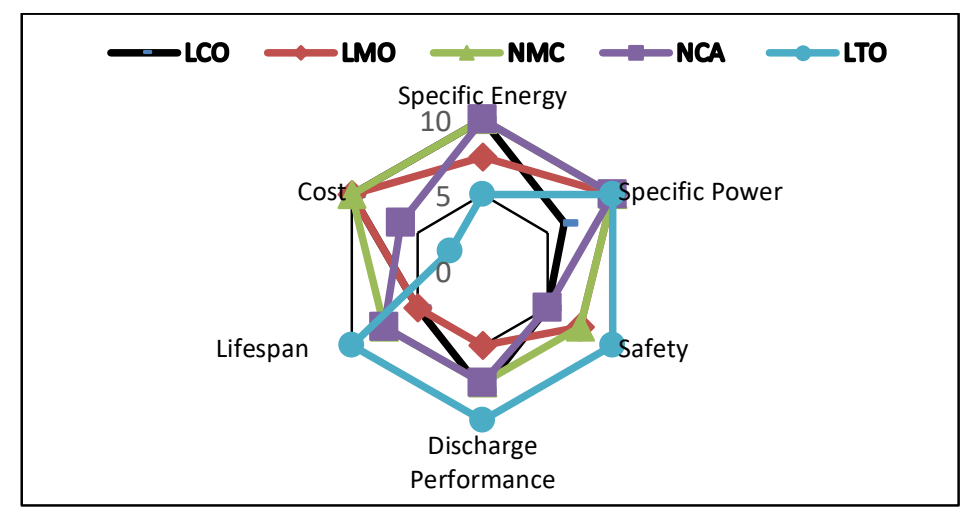

Figure 3. The performance level of different lithium battery types

\section{THE BATTERY CHARGING AND MANAGEMENT SYSTEM}

\subsection{Charging Technique}

Battery charging system restores energy through electrochemistry reaction process in the lithium-ion based battery cell. The battery cell requires a reliable charging technique to ensure the process is safe and fast while preventing battery overheating [25]. There are lots of charging technique reported in the literature. The main of this field of study is to minimize the time to charge the battery system while ensuring safety and maximizing the lifespan of the battery during the process. Several charging techniques such as the constant current-constant voltage (CC-CV), the varying current (VC), the multistage charge (MC), and four-stages constant current (FCC) are discussed in this paper.

The CC-CV charging technique is the most common charging technique applied in practice. It is considered in various application because of its simplicity as compared to other techniques. Subsequently, the methods provide a steady voltage to the battery in the constant voltage phase with a constant voltage to avoid overcharging occurs. However, the researchers in [26] found that this method may cause metallic lithium plating at the end of the constantcurrent charging phase. The metallic lithium plating may lead to a short circuit and consequently degrading the battery's lifespan. The VC charging method is developed to charge the degraded lithium-ion battery. The degraded battery has developed higher overpotential resistance over time and change the predefined energy bound of the battery due to the permanent chemical reaction inside the battery. Therefore, the CC-CV method is not suitable to charge this battery because it is unable to determine a new predefine energy bound that been consumed by equivalent overpotential resistance [27]. Consequently, the high equivalent overpotential resistance causes energy loss during the charging process. The VC technique adapts the energy bound during the charging process and provides the charging current accordingly by calculating the equivalent overpotential resistance of the battery. Then, the charging current is updated to match the estimated energy-bound time consumption and end-of-charge time. In short, the VC technique limits the energy-bound loss and increase efficiency during the charging process. Although the degraded battery may no longer suitable for its initial purpose, it may be suitable for other application [28]. 
The MC charging method is designed to improve the $\mathrm{CC}-\mathrm{CV}$ method for its poor charging performance at the low-temperature condition. At this condition, the battery chemical reaction is decreased, while the internal resistance of the battery is increased. The increment of the battery internal resistance causes the CC-CV method to detect the cut-off voltage limit earlier than the charging process during normal charging condition. This will terminate the charging process before the battery is fully charged [29]. The MC method addresses this limitation by decreasing the charging rate when the voltage terminal almost reached the cut-off voltage limit. This process is realized by systematically reduce the charging current until it reaches the lowest charging current limit. Due to this process, the $\mathrm{MC}$ method requires longer charging time as compared to the $\mathrm{CC}-\mathrm{CV}$ method [30]. The FCC charging technique improves the charging performance of the MCM method by minimizing the time and increasing the efficiency of the charging process. The method is based on the integration of the Taguchi method and the state estimation of battery SOC. The method operates by determining the optimal charging current and the predefined cut-off voltage and adapt the charging process accordingly at each charging stage [31]. The FCC technique provides a higher and safer constant current rate in different charging stage to reduce the charging time without damaging the battery cell from overcharging. Therefore, FCC is an excellent option for the ESS system for the residential RE application due to its superior performance as compared to other charging methods.

\subsection{Battery Management System}

As discussed in Section 3, the lithium battery is not a perfect energy storage system. However, due to its superior specific energy, specific power, discharge performance, and cost, it is preferred as the battery of choice for the future ESS. It is also discussed that the lithium battery is not the best options in terms of the safety and the lifespan of the battery. However, these issues could be addressed with proper management of battery charging and discharging processes by considering the BMS. A basic responsibility of a BMS is to ensure that the energy stored in the battery is used optimally and the risk of damage to the battery is prevented by controlling the battery's charging and discharging process. Figure 4 shows the typical BMS configuration. The system discussed in this paper is based on the fundamental working principle of the BMS. There are lots of more advanced system with different configuration available in practice [32-34]. However, the working principle is relatively the same. From the figure, it is shown that the BMS consists of four critical sub-systems: monitoring, state-estimator, cell balancing, and temperature.

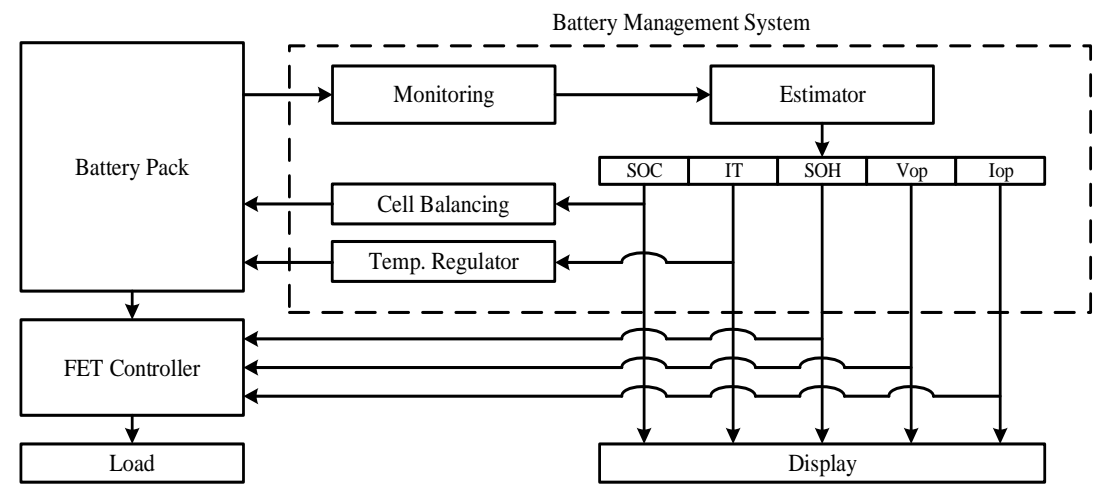

Figure 4. Typical BMS configuration

The monitoring system gathers the vital information system from the battery pack, which are the voltage across each cell, the voltage across the battery pack, the current, and the temperature of the battery pack. For a simpler BMS, these measured data are directly used to provide the information for the cell balancer, the temperature regulator and the field effect transistor (FET) controller to control the charging and discharging processes of the battery pack. However, this simple BMS is only enough for the battery application under a static operating environment. A smarter or advanced BMS is required for the system operating under dynamic operating environment [35]. In an advanced BMS, the measured data from the monitoring system are sent to the state-estimator in order to provide an adaptive control on the battery utilization based on its real-time state. This is realized by using a proper state estimation technique to provide appropriate control that suits the current battery condition. In order to provide such control, the real-time state of charge (SOC), state of health (SOH), and internal temperature (IT) of the battery should be first estimated [36].

All these estimations and information are transfer either to the cell balancer, temperature regulator, or FET controller. The cell balancer is important to ensure that each cell is charged with the same SOC. Usually, there are $1 \%$ or $2 \%$ mismatch of the cell's internal resistance when a pack is constructed [37]. Thus, if a cell has a higher 
SOC relative to its neighbors, resistors in parallel with each cell are switched on to dissipate energy unnecessarily. The temperature regulator requires IT estimation to regulate the temperature. Heating the battery pack up is as important as cooling it down especially during the charging process. Charging the lithium battery at low temperature may cause the lithium to plate instead of to intercalate with the anode [38]. This unwanted process causes specific energy reduction and the internal resistance increment of the battery. On the other hand, the FET controller acts as the gateway to control the utilization of the energy in the battery pack based on the input from the estimator and the monitoring system.

\section{DISCUSSION AND CONCLUDING REMARK}

The research on the residential RE system depends on the advancement of the ESS. In this paper, the latest update on the practical options and the advancement of the crucial technologies for the ESS are discussed in detail. The suitability of these technologies depends on various factors such as the operating situation, the tariff system used, and the geo-location of the system. These factors affect the frequency of charging-discharging cycles of residential RE. Thus, the ESS system equipped with the RE system needs to be able to allow such operation safely. The critical characteristics to look for in battery chemistry that suits this application are the battery lifespan and safety. From the discussion, LTO is the most suitable battery chemistry for the residential RE application. However, from the business perspective, the cost to produce LTO battery is the highest compared to other battery. LTO also has the lowest specific energy, which implies that the total cost of the system is higher for the same size of storage. Alternatively, one could consider NMC as the preferred battery chemistry for the residential RE application. Although it is not as best as LTO in terms of lifespan and safety (LTO rated 10, while NMC rated 8 for both characteristics, respectively), the cost and specific energy of NMC are far superior. As discussed in Section 4, an advanced battery charging, and management system can prolong the lifespan and ensure the safety of the NMC battery operation. The size of the battery system for the RE system is relatively huge as compared to the mobile application. Thus, as the cost required to replace the battery is linearly dependent to the size, it is necessary to consider an advanced battery's charging and management system to maximize the lifespan and the safety of the battery. One could consider the FSCC charging method because it can adapt the charging current according to the battery's SOC.

Extensive efforts have already been in place to address the difficulty of increasing the techno-socioeconomical readiness levels of the ESS for the residential RE system. Research for the battery storage system, and the battery management system is very active. For instance, new battery chemistry and design are being developed to achieve higher performance. The new state-estimation algorithm to estimate the real-time condition of the battery is also an active research field, which is crucial to the performance of the BMS. The advanced machine learning such as deep-learning method and reinforcement learning should be considered in the development of the future intelligent BMS to improve the performance of the ESS. The development of the intelligent BMS system should also facilitate the integration of supercapacitor in the future ESS to allow instantaneous charging capability. The literature in the ESS is very rich and are continuous and rapidly changing. The advancement of the ESS is crucial to the penetration of RE into the electricity market share. The increase in market penetration and the increase in process learning curves are coming into effect will progressively decrease the dependency on the fossil-fuel for electricity in the future

\section{ACKNOWLEDGMENTS}

The authors would like to thank Universiti Tun Hussein Onn Malaysia (UTHM), Johor and Ministry of Education (MOE) Malaysia for the award of the grant that enabled this research under the grant No. H208 and U952.

\section{REFERENCES}

[1] N. Patel, "Environmental and economical effects of fossil fuels," in Journal Journal of Recent Research in Engineering and Technology, vol. 1, no. 7, pp. 2349-2260, 2014.

[2] B. Scrosati and J. Garche, "Lithium batteries: Status, prospects and future," in Journal of Power Sources, vol. 195, no. 9, pp. 2419-2430, 2010.

[3] T. N. Berhad, "Tenaga Nasional Berhad : Integrated annual report 4-month period ended 31 December 2017," 2017. [Online]. $\quad$ pp. 38-42. Avaiable https://www.tnb.com.my/assets/annual_report/TNB_AR2017_4MONTH_PERIOD_ENDED_31_DECEMBER_20 17.pdf

[4] M. Joos and I. Staffell, "Short-term integration costs of variable renewable energy : Wind curtailment and balancing in Britain and Germany," in Renewable and Sustainable Energy Reviews, vol. 86, pp. 45-65, 2018.

[5] S. Vazquez, et al., "Energy storage systems for transport and grid applications," in IEEE Transactions on Industrial Electronics, vol. 57, no. 12, pp. 3881-3895, 2010. 
[6] H. Chen, et al., "Progress in electrical energy storage system: A critical review," in Progress in Natatural Science, vol. 19, no. 3, pp. 291-312, 2009.

[7] V. V. Garita, et al., "Review of residential PV-storage architectures," in Proceeding IEEE International Energy Conference (ENERGYCON 2016), pp.1-6, 2016.

[8] T. T. Nguyen, et al., "A review on technology maturity of small scale energy storage technologies," in Renewable Energy and Environment Sustainability, vol. 2, no. 36, pp. 1-7, 2017.

[9] A. A. Mahmoudzadeh, "A review of battery electric vehicle technology and readiness levels," in Renewable and Sustainable Energy Reviews, vol. 78, pp. 414-430, 2017.

[10] P. Nikolaidis and A. Poullikkas, "A comparative review of electrical energy storage systems for better sustainability," in Journal of Power Technologies, vol. 97, no. 3, pp. 220-245, 2017.

[11] A. Goodrich, T. James, M. Woodhouse, "Utility-scale photovoltaic (PV) system prices in the United States: Current drivers and cost-reduction opportunities," in National Renewable Energy Laboratory, chap 4, pp. 23-34, 2012.

[12] I. Staffell and M. Rustomji, "Maximising the value of electricity storage," in Journal of Energy Storage, vol. 8, pp. 212-225, 2016.

[13] P. Rajendran and H. Smith, "Review of solar and battery power system development for solar-powered electric unmanned aerial vehicles," in Advance Material Research, vol. 1125, pp. 641-647, 2015.

[14] R. Gopalakrishnan et al., "A comprehensive study on rechargeable energy storage technologies," in Journal of Electrochemical Energy Conversion and Storage, vol. 13, no. 4, pp. 1-25, 2017.

[15] T. Horiba, "Lithium-ion battery systems," in Proceeding of the IEEE, vol. 102, no. 6, pp. 1-12, 2014.

[16] S. Flandrois and B. Simon, "Carbon materials for lithium-ion rechargeable batteries," in Elsevier Carbon, vol. 37, no. 2, pp. 165-180, 1999.

[17] D. Choi, et al.,"Low cost, long cycle life, li-ion batteries for stationary applications," in Energy Storage Program Annual Update (DOE EERE 2010), November 2, 2010.

[18] "Tesla and Panasonic Collaborate to Develop Next-Generation Battery Cell Technology," Tesla. [Online]. Available: https://www.tesla.com/blog/tesla-and-panasonic-collaborate-develop-nextgeneration-battery-celltechnology.

[19] G. E. Blomgren, "The development and future of lithium ion batteries," in Journal of Electrochemical Society,vol. 164, no. 1, pp. A5019-A5025, 2017.

[20] N. Nitta, et al., "Li-ion battery materials : present and future," in Materials Today, vol. 18, no. 5, pp. 252-264, 2015.

[21] C. H. Chen, et al., "Aluminum-doped lithium nickel cobalt oxide electrodes for high-power lithium-ion batteries," in Journal of Power Sources, vol. 128, no. 2, pp. 278-285, 2004

[22] G. Berckmans, et al, "Cost projection of state of the art lithium-ion batteries for electric vehicles up to 2030," in Energies, vol. 10, no. 9, 2017.

[23] P. A. Dias, D. Blagoeva, and C. Pavel, "Cobalt : Demand-supply balances in the transition to electric mobility," in European Commission Joint Research Center (JRC), pp. 5-27, 2018.

[24] M. Safari and A. Hardy, "Expert talk: Battery storage in the energy transition," in the Energyville Battery Research, 2019. [Online]. Available: https://www.energyville.be/en/press/battery-storage-energy-transition.

[25] A. A. Hussein and I. Batarseh, "A review of charging algorithms for nickel and lithium battery chargers," in IEEE Transaction on Vehicular Technology, vol. 60, no. 3, pp. 830-838, 2011.

[26] S. S. Zhang, "The effect of the charging protocol on the cycle life of a li-ion battery," in Journal of Power Sources, vol. 161, no. 2, pp. 1385-1391, 2006.

[27] J. H. Yen, et al., "The prototype implementation of a varying current charger for aged rechargeable lithium-ion batteries," in Proceedings of International Conference on Consumer Electronics, Communications and Networks (CECNet 2011), no. 1, pp. 5421-5424, 2011.

[28] L. Gaines, "The future of automotive lithium-ion battery recycling: Charting a sustainable course," in Sustainable Materials and Technology, vol. 1, no. 2, pp. 2-7, 2014.

[29] X. Wu, et al., "Multistage CC-CV charge method for li-ion battery," in Mathematical Problem in Engieering, vol. 52, pp. 1-10 2015.

[30] P. Keil and A. Jossen, "Charging protocols for lithium-ion batteries and their impact on cycle life-An experimental study with different 18650 high-power cells," in Journal of Energy Storage, vol. 6, pp. 125-141, 2016.

[31] D. Anseán, et al., "Efficient fast-charging strategies for Li-ion batteries," in International Electrical Vehicle Symosium and Exhibition (EVS28 2015), May 3-6, 2015.

[32] A. H. Ali, et al, "A smart monitoring and controlling for agricultural pumps using LoRa IOT technology," in Indonesian Journal of Electrical Engineering and Computer Science, vol. 13, no. 1, pp. 286-292, 2019.

[33] M. R. B. Khan, et al, "Energy management system for PV-Battery microgrid based on model predictive control," in Indonesian Journal of Electrical Engineering and Computer Science, vol. 15, no. 1, pp. 20-25, 2019.

[34] A. H. Ali et al., "System protection for Lithium-ion batteries management system : a review," in Indonesian Journal of Electrical Engineering and Computer Science, vol. 13, no. 1, pp. 1184-1190, 2019.

[35] C. Chen et al., "Design and realization of a smart battery management system," in Proceedings of the International Multi Conference of Engineers and Computer Scientist (IMECS 2012), March 14-16, 2012.

[36] K. Liu, et al., "A brief review on key technologies in the battery management system of electric vehicles," in Frontier of Mechanical Engineering, pp. 1-18, 2018.

[37] S. Santhanagopalan, et al., Design and Analysis of Large Lithium-Ion Battery Systems, 1st Edition, Boston London, Artech House, 2014, Chap 7, pp. 176-177. 
[38] Y. Bultel, et al., "Irreversible capacity loss of li-ion batteries cycled at low temperature due to an untypical layer hindering li diffusion into graphite electrode," in Journal of Electrochemical Society, vol. 164, no. 12, pp. A2374A2389, 2017

\section{BIOGRAPHIES OF AUTHORS}

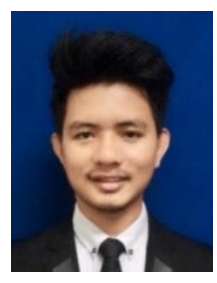

M. S. A. Mustaza received the B.Eng. degree in electrical engineering (Hons.) in electrical power from Universiti Tun Hussein Onn Malaysia (UTHM), in 2017. Currently, he is a student in Universiti Tun Hussein Onn Malaysia (UTHM) for M. Eng degree in electrical power engineering. His current research interests include renewable power system, energy storage system and adaptive control system for residential.

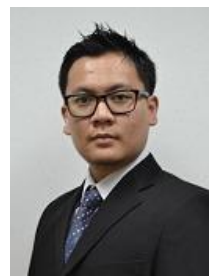

M. A. M Ariff received the B.Eng. degree in electrical engineering (Hons.) and the M.Eng degree in electrical power from Universiti Teknologi Malaysia (UTM), in 2008 and 2010, respectively, and the Ph.D. degree from Imperial College London, London, U.K., in 2014. Currently, he is a Senior Lecturer with Universiti Tun Hussein Onn Malaysia (UTHM), Batu Pahat Johor, Malaysia. His current research interests include power system dynamics, coherency identification, adaptive protection in power system, and controlled separation for blackout prevention. Currently, he is Editor of the IEEE Power and Energy Systems Journal.

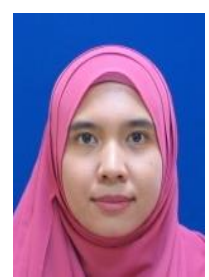

Sofia Najwa Ramli is currently a lecturer at the department of Information Security and Web Technology, Universiti Tun Hussein Onn Malaysia, Batu Pahat. She received her PhD in Information and Communication Technology from Universiti Teknikal Malaysia Melaka in 2016 and Master's degree (M. Eng) in Electrical, Electronics and Telecommunications from Universiti Teknologi Malaysia in 2010. Her research interests include cyber-physical system, Wireless Body Area Network, authentication, biomedical signal processing and cryptography. She has delivered articles in various international conferences and journals as well as a reviewer in various IEEE journals. 